training. Most practitioners who had graduated from private institutions confessed that they had little experience in handling routine clinical situations. The patient inflow in many private colleges did not allow for adequate training in clinical procedures. Poor training had contributed to low confidence and subsequently to fear of practice.

Some diary entries described how they felt "inadequate and incompetent" as healthcare practitioners. The tone and language reflected disillusionment and dejection. In addition to emotional accounts of "not belonging" to the profession, there were conclusions such as "Maybe I am not suited for this profession" and "Joining this course was a huge mistake in life." The same emotional breakdowns, uncertainties and fears were expressed in face-to-face interviews.

My technical skills are poor. I didn't seen many cases in my college, since there was poor patient inflow there. Now I am paying money to the government to work here after graduation so I get to see more cases and improve my skills. I am trying, but I am not confident. I don't know if I am good enough. I mean, we are dealing with real human beings. I don't think I will survive in this field for long.

(Senior resident currently working in a public health facility)

\section{The researcher's distress}

In this study, reflection was used as a research method to explore participants' thought processes regarding their current performance as clinicians. The researcher's intention was to generate recommendations to improve the training and curriculum of this branch of medical education so that graduates would be better prepared to suit the demands of their profession. However, while making the diary entries, the participants developed certain views about their choices and training which they connected to their current performance. The reflections also indicated that the participants considered their training to be compromised in many areas. None of this had been anticipated by the researcher.
The researcher was distressed by some participants' selfdescriptions as "a failure", "incompetent", with "no future in the field". She was concerned that this would result in lasting damage to their lives and careers.

Some participants expressed their intention to leave the field in which they had trained, and pursue other interests. However, many had taken loans for this expensive training; they also had to face the expectations of their families and society. Hence at this stage in their lives, leaving their current profession and pursuing other options could have terrible personal consequences.

The researcher was also concerned about the possibility that if the graduates had not engaged in this exercise, they would have come to terms with their inadequacies over time, worked on them and emerged successful.

With two weeks left of the exercise, the researcher wondered if she should dissuade at least those participants who had responded strongly in their entries from continuing the reflection process. It was possible that the more time spent reflecting, the more convinced they would become of their own inadequacies.

\section{Questions raised by the case}

1. Can this be considered a case of research-induced harm?

2. Could the researcher have taken steps before and during the research to prevent the harm or reduce it?

3. What can the researcher do at this point to address the participants' feelings?

\section{References}

1. Morley C.Critical reflection as a research methodology. In:Liamputtong $\mathrm{P}$, Rumbold J, editors. Knowing differently: arts-based and collaborative research methods. New York: Nova Science Publishers, Inc; 2008. pp 26580.

2. Hewitt E. Building bridges: the use of reflective oral diaries as a qualitative research tool. International Journal of Research \& Method in Education. 2015 Nov; 40(4):1-15. Doi: 10.1080/1743727X.2015.1114601

\title{
Using critical reflection in public health research: Identifying and mitigating emotional harms
}

\section{VIJAYAPRASAD GOPICHANDRAN}

Author: Vijayaprasad Gopichandran (vijay.gopichandran@gmail.com), Assistant Professor, Department of Community Medicine, ESIC Medical College and PGIMSR, KK Nagar, Chennai 600078 INDIA.

To cite: Gopichandran V. Using critical reflection in public health research: identifying and mitigating emotional harms. Indian J Med Ethics. 2020 JanMar; 5(1) NS:20-1.DOI: 10.20529/IJME.2020.015.

Peer Reviewer: Manjulika Vaz

@Indian Journal of Medical Ethics 2020
Keywords: Critical reflection, mitigating harm, qualitative research, diary entries, professional distress, research-induced harm, anticipating research problems

Malu Mohan has described the distress faced by the researcher who attempted to study the practice preparedness of recent graduates of a stream of clinical practice through critically reflective diary entries (1). The graduates realised that they were grossly underprepared for competent and 
independent clinical practice. The researcher's distress arises from the dilemma as to whether she has precipitated a sense of "incompetence" and "hopelessness" among the fresh graduates, causing unintended harm. It is commendable that the researcher has introspected seriously on the consequences of her study. I would like to comment on the specific ethical conflict faced by the researcher in this case and the possible mitigative measures that could have been undertaken. I will also try to derive broader inferences for the use of critical reflection in public health research.

This study has been conducted against the background of intense commercialisation of medical education and a burgeoning of graduates and private practices in the field. It is well known that in private medical institutions, patient numbers are much lower than in public institutions, providing fewer opportunities to learn skills and procedures. So, the researcher as well as the ethics committee reviewing this research proposal must have considered that at least some of the recent graduates are likely to find themselves ill-equipped for independent practice. The researcher has embarked on the study with the specific objective of probing this aspect Given the intense competition in the market, it is also natural to expect those graduates who perceive themselves as underprepared to experience substantial distress.

The benefit-risk assessment in qualitative research studies is often ignored or performed in a perfunctory manner. It is not uncommon to find the statement, "this qualitative study lacks any major risks for the participant" in many qualitative research proposals. Some of the benefits of qualitative research are, enhanced understanding of the self through reflection, selfexpression and sharing of one's opinions, and acquisition of new knowledge and skills through participation in the study. Some of the common risks of qualitative research are, breach of confidentiality, emotional and social distress because of reliving some sensitive or traumatic experiences, risk of misunderstandings and misinterpretations (2-5). Therefore, a more thorough ethical reflection on the proposed research could have helped the researcher as well as the ethics committee identify and anticipate this important ethical conflict.

Once identified, the researcher could have instituted mitigative measures against the distress that the reflective diary elicited in the participants. She could have involved a career counsellor a senior practitioner-mentor in the field, or a psychologist, to provide emotional and psychological support for the participants. She could have read early signs of such distress in the reflective diaries and encouraged the participants to seek help. Moreover, she could have channelised this distress among the young graduates into a motivation to enrol in clinical training or capacity building courses to improve their skills.

Another important ethical dimension of this type of research is identifying whether such a critical reflection exercise is a research or non-research educational activity. Reflective practice of medicine is defined as the process where the practitioner studies and reflects on their own experiences to learn from them and to improve their responses to specific situations. In the medical profession, where there is a need for constant reflection in order to be a life-long learner, reflective practice is essential (6). In fact, the Attitudes Ethics and Communication (AETCOM) module, introduced by the Medical Council of India into the medical curriculum from 2019, lays a lot of emphasis on reflective writing by medical students in the area of medical ethics and professionalism (7). Therefore, one could view this research as being on the interface of research and practice. In such situations, it is important to provide opportunities to research participants to complete their learning cycle using the reflective writing exercise.

One more ethical conflict which the researcher is facing here arises from her intimate knowledge of low preparedness and professional insecurity among some of the practitioners. The researcher must also think about what her role in this situation is. Should she let these under-prepared young graduates be, or should she organise a refresher course for them with more hands-on training? Does this researcher have a responsibility to the community which is served by the under-prepared practitioners? Such a reflection should have taken place at the stages of designing the study and of ethics review. The researcher should have put in place followup action for participants who find themselves unprepared. On a related note, the researcher may also incidentally find lack of competence among the practitioners, outside of the purview of her research. In other words, rather than from selfreflection in the diary, the knowledge of poor competence may emerge from some other observation, or casual discussion. Such a finding is referred to as an ancillary finding. What is the responsibility of the researcher in such a situation? All these ideas should be discussed in detail before beginning a study.

I think the idea that the researcher must stop the respondentpractitioners from performing any further reflection is unhealthy. Rather than stopping them from proceeding with the reflection, she must now involve a professional career counsellor or senior mentor as mentioned earlier and help those whom she thinks are in imminent danger of quitting the profession. Though in this case, the distress caused by the self-reflection is research-induced harm, it is important to remember that while reflective practice can be distressing, that distress is the first step in changing oneself for the better. The only problem in this research study was that this reflectioninduced distress was not anticipated and supports were not put in place. If proper supports are in place, such a reflection will result in positive outcomes for the participants.

Critical reflection has been used for improvement of the quality of work of healthcare professionals, including community health workers and other healthcare providers. Reflective writing has been used as an integral part of qualitative research. It is sometimes used as a primary data source when participants write reflective journals, as in this case study. At other times, the researchers themselves maintain reflective journals of their experiences of conducting a study (8). It is likely that such reflective writing could induce similar 
emotional responses in the writer. Therefore, before embarking on any qualitative research that employs reflective writing, one must keep in mind the risk of causing emotional distress in the writer and proper mitigative measures must be put in place.

\section{Reference}

1. Mohan M. Use of critical reflection as a research method: a case of research-induced distress? Indian J Med Ethics. 2020 Jan-Mar;5(1) NS:1920.DOI: 10.20529/IJME.2020.014.

2. Birch M, Miller T. Inviting intimacy: The interview as therapeutic opportunity. Int J Soc Res Methodol. 2000 Nov; 3(3): 189-202.

3. Campbell R, Adams AE, Wasco S M, Ahrens C E, Sefl T."What has it been like for you to talk with me today?": The impact of participating in interview research on rape survivors. Violence Against Women, 2010 Jan;
16(1):60-83.

4. Cook AS, Bosley G. The experience of participating in bereavement research: Stressful or therapeutic? Death Stud. 1995 Mar-Apr: 19(2), 157-170.

5. Ellis C. Telling secrets, revealing lives relational ethics in research with intimate others. Qual Inq. 2007 Jan; 13(1): 3-29.

6. Koshy K, Limb C, Gundogan B, Whitehurst K, Jafree DJ. Reflective practice in health care and how to reflect effectively. Int J Surg Oncol (N Y). 2017 Jul; 2(6):e20. doi: 10.1097/IJ9.0000000000000020.

7. Medical Council of India.AETCOM - Attitude Ethics and Communication. Competencies for the Indian Medical Graduate. New Delhi: MCl;2018 [cited 2020 Jan 20]. Available from: https://www.mciindia.org/CMS/wpcontent/uploads/2019/01/AETCOM_book.pdf

8. Jasper M A. Using reflective writing within research. J Res Nurs. 2005 May;10(3):247-60.

\section{Ancillary findings during public health research: A researcher's ethical dilemma}

\section{NEETHU SURESH}

Keywords: Ancillary findings, anticipating research problems, anonymity, protecting participants, confidentiality

\section{Background}

Sometimes researchers investigating one matter come across other issues in the course of their work. Such findings, not directly related to the subject of research, are called ancillary findings. Researchers encountering ancillary findings may face ethical dilemmas on how to act upon these findings.

\section{The case}

A researcher was investigating the effectiveness of oral health education on the oral hygiene status of 6- to 12-year-old school children studying in government and governmentaided schools in a South Indian state. The researcher conducted focus group discussions with teachers in 16 schools, to understand the dietary habits of children as these can affect their oral health. The participants were promised that the information they provided would be kept confidential and used only for research purposes.

As part of the school meal programme, the government provides lunch and breakfast to school children. School authorities also have the responsibility of providing safe drinking water to the children. During the focus group

Author: Neethu Suresh (neethusuresh@ymail.com), PhD Scholar, Achutha Menon Centre for Health Science Studies, Sree Chitra Tirunal Institute for Medical Sciences and Technology, Thiruvananthapuram, Kerala, 695 011, INDIA.

To cite: Suresh N. Ancillary findings during public health research: a researcher's ethical dilemma. Indian J Med Ethics. 2020 Jan-Mar;5(1) NS: 22-3. DOI: 10.20529/IJME.2020.016.

OIndian Journal of Medical Ethics 2020 discussions with teachers, the researcher found that even though care was taken to provide a healthy breakfast and lunch to the school children, not all schools ensured safe drinking water.

Only one out of the 16 schools was taking adequate steps to provide safe drinking water to children throughout the school hours. In each classroom in that school, boiled water was provided in a pot along with a glass, so that children had access to safe drinking water throughout school hours.

In the remaining schools, children faced difficulties in obtaining safe drinking water. In most schools, boiled water was kept in the kitchen, but in some of these schools the kitchen was locked by $3 \mathrm{pm}$. After $3 \mathrm{pm}$, children depended on tap water or remained thirsty till they reached their homes. In some schools there was a long distance between the classrooms and the kitchen, so children did not have easy access to safe drinking water.

Rural schools which depended entirely on well water faced water shortages in the summers. In these schools, when the power went off they were not able to pump well water. School authorities had therefore instructed children to bring two bottles of water from home, one for drinking and the other for washing their tiffin plates.

The teachers' justified not providing safe drinking water to the children saying that the children could bring water from their homes, and that drinking tap water does not cause any problems; there was not enough fuel to boil water; it was difficult to carry the heavy water-filled jars from the kitchen to the corridor, and there was a water shortage.

Drinking unsafe water can cause many gastrointestinal problems including vomiting and diarrhoea. Moreover, access to safe drinking water is the right of every child. In schools, it 